\title{
Exclusive and concurrent use of cigarettes and alternative tobacco products among Hong Kong adolescents
}

\author{
Nan Jiang' ${ }^{1}$ SY $\mathrm{Ho}^{2}$, Man Ping Wang' ${ }^{2}$ Lok Tung Leung ${ }^{2}$, Tai Hing Lam²
}

\begin{abstract}
INTRODUCTION The use of alternative tobacco products (ATPs) is becoming increasingly popular among the youth. This study aimed to assess cigarette-only smoking, exclusive ATP use, and concurrent use (cigarettes and ATPs) among adolescents in Hong Kong.

METHODS We analyzed data of the Hong Kong School-based Survey on Smoking among Students 2012/13 from a representative sample of 45857 secondary school students. Weighted prevalence of cigarette-only smoking, exclusive ATP use, and concurrent tobacco use were calculated. Multinomial logistic regression examined correlates of exclusive ATP use and concurrent use relative to cigarette-only smoking. Among current (past-30-days) cigarette smokers, multivariable logistic regression assessed whether ATP use was associated with nicotine dependence, quit intention and quit attempt.

RESULTS Overall, $5.8 \%$ of adolescents reported current tobacco use (2.1\% cigaretteonly smoking, $2.5 \%$ exclusive ATP use and $1.2 \%$ concurrent use). Compared with cigarette-only smoking, exclusive ATP use and concurrent tobacco use were associated with younger age, higher perceived family financial status, absence of cigarette smoking peers, poor knowledge about smoking and more frequent alcohol use. Among current cigarette smokers, ATP use was negatively associated with cigarette quit intention and quit attempt.

CONCLUSIONS ATP use was as prevalent as cigarette smoking among adolescents, and ATP users were different from cigarette smokers in many demographic and psychosocial factors. Tobacco control programs among youth should target different types of tobacco users and address all forms of tobacco products.
\end{abstract}

\section{INTRODUCTION}

Tobacco use often begins in adolescence ${ }^{1}$. Today, the pattern of youth tobacco use has become more complex than ever before as alternative tobacco products (ATPs), such as electronic cigarettes (e-cigarettes) and waterpipe, gain increased popularity. From 2011 to 2014 , waterpipe smoking has doubled and e-cigarette use has increased more than 5-fold among U.S. middle and high school students $^{2,3}$. In Poland ${ }^{4}$ and New Zealand ${ }^{5}$, e-cigarette use has tripled among school students. A common reason for ATP use is that young people perceive ATPs as less harmful and less addictive than cigarettes ${ }^{1}$. However, ATPs may contain carbon monoxide, carcinogens and other toxicants ${ }^{6-8}$. ATPs often contain nicotine ${ }^{9}$, and therefore, ATP use is associated with increased likelihood of nicotine dependence ${ }^{8,10-12}$, especially when used concurrently with cigarettes ${ }^{1,12}$.

ATP use often occurs in combination with cigarette smoking, but exclusive ATP use is also prevalent ${ }^{13-15}$. Data from the 2012 U.S. National Youth Tobacco Survey showed that $14.6 \%$ of secondary school students were current (past-30-days) tobacco 
users, including $2.8 \%$ cigarette-only smokers, $5.3 \%$ exclusive ATP users, and $6.4 \%$ concurrent tobacco users (cigarettes and ATPs) ${ }^{16}$. Few studies have compared the characteristics of different types of tobacco users. Wickholm et al. ${ }^{17}$ compared cigaretteonly smokers, exclusive snus users and concurrent users (cigarettes and snus) among Swedish boys and concluded that the rates of alcohol use and frequent binge drinking were highest among concurrent users and lowest among cigarette-only smokers. Cavazos-Regh et al. ${ }^{18}$ compared non-tobacco users, cigarette-only smokers, exclusive ATP users and concurrent users (cigarettes and ATPs) among U.S. adolescents and found that cigarette-only smokers and exclusive ATP users were no different in alcohol abuse disorders, but cigarette-only smokers were more likely to report marijuana and other illicit drug use disorders.

Information regarding other psychosocial factors related to the different types of tobacco users remains unknown. Moreover, ATP use has been insufficiently explored among Asian populations. Hong Kong, the most westernised city of China, has remarkably a low prevalence of daily cigarette smoking (10.5\% in 2015 among residents aged 15 years or older ${ }^{19}$. Smokeless tobacco products are prohibited for manufacture, importation and sale in Hong Kong ${ }^{20}$. However, e-cigarettes have become increasingly available in retail stores, through social media and online stores ${ }^{21}$ and waterpipe lounges have spread widely in recent years $^{22}$. E-cigarette use and waterpipe smoking are prohibited in statutory smoke-free areas ${ }^{23}$. Waterpipe is regarded as a type of pipe by the Hong Kong Smoking (Public Health) Ordinance and subject to similar regulations including excise tax, health warnings and restriction of sale to people under 18 years old. However, enforcement of these regulations is uncertain and waterpipe smoking in waterpipe lounges is common ${ }^{24}$. Flavored tobacco is often used for waterpipe smoking in Hong Kong ${ }^{24}$ but the nicotine content of such products is commonly unclear and may not correlate with the plasma nicotine level of users ${ }^{25}$. E-cigarettes containing nicotine are regulated as pharmaceutical products, which must be registered with the Pharmacy and Poisons Board of Hong Kong before sale and distribution. As of February 2018, no one has applied for a license to sell nicotine-containing e-cigarettes in Hong Kong. However, people can easily get nicotine-containing e-cigarettes through retail or online stores. Some e-cigarettes available on the market may be labeled as nicotine-free just to bypass the regulation. A recent study assessed the chemicals of 13 brands of e-cigarettes bought in Hong Kong and found that they contained nicotine at levels of $3.5-28.5 \mathrm{ng} / \mathrm{mL}^{26}$. The low cigarette smoking rate and the increased availability of e-cigarettes and waterpipe in Hong Kong makes it a unique case to explore the different types of youth tobacco users and their characteristics.

In this study, we examined the prevalence of cigarette-only smoking, exclusive ATP use, and concurrent use of cigarettes and ATPs in a large representative sample of secondary school students in Hong Kong. We assessed the factors associated with exclusive ATP use and concurrent tobacco use compared with cigarette-only smoking. Findings may help improve our understanding about the characteristics of different tobacco users and help to develop tailored tobacco cessation interventions among adolescents.

\section{METHODS}

\section{Data source}

We analysed data from Hong Kong School-based Survey on Smoking among Students 2012/13 (hereafter referred to as 'the Survey'). This biennial cross-sectional survey was developed based on the Chinese version of the Global Youth Tobacco Survey and aimed to monitor tobacco use patterns among primary (US grades 4-6) and secondary (US grades 7-12) school students in Hong Kong. The Survey used a proportionate stratified sampling method to get a representative sample of school students. Special schools (for adolescents with visual, hearing and other physical impairments or disabilities) were excluded. The Survey was approved by the Institutional Review Board of the University of Hong Kong/Hospital Authority Hong Kong West Cluster. Details regarding the Survey have been described elsewhere ${ }^{27,28}$.

The 2012/13 Survey was conducted from October 2012 to April 2013. Students from the participating schools were invited to voluntarily complete an anonymous questionnaire. Alternative tobacco use was assessed among secondary school students 
only. Thus, our analysis was limited to students in secondary schools ( $\mathrm{N}=45857)$. The response rate was $19 \%$ at school level and $96 \%$ at student level. School refusals were mainly due to busy school schedules, which did not allow students' participation in the Survey during normal school hours. We compared the sample characteristics (e.g. age, sex and grade distribution) with 2012/13 Hong Kong school student enrollment data. The small Cohen's effect size (ranging from 0.05 to 0.21 ) indicated that the sample represented well the student population. Similarly, we compared the characteristics of participating schools (i.e. school type, district, financial description and student sex distribution) with Hong Kong Education Bureau's official data using Cohen's effect size, the values (ranging from 0.13 to 0.44 ) suggested that the participating schools were similar to all other schools.

\section{Main measures}

Current cigarette smoking was assessed by asking: 'In the past 30 days, on how many days did you smoke?' Response options included '0 day', '1-2 days', ' $3-5$ days', '6-9 days', '10-19 days', '20-29 days' and '30 days'. Those who reported smoking on at least one of the past 30 days were defined as current cigarette smokers. ATP use was assessed by the question: 'In the past 30 days, which of the following products have you used?'. Options included e-cigarettes, waterpipe, chewing tobacco, cigars, snus, smoking pipe, nasal snuff and other (non-cigarette) tobacco products. Students who reported using any noncigarette tobacco products were defined as ATP users. Students who reported cigarette smoking or ATP use within the past 30 days were defined as current tobacco users and were categorized into 3 groups: 1) cigarette-only smokers, 2) exclusive ATP users, and 3) concurrent tobacco users (cigarettes and at least one form of ATP).

Students were also asked: 'During the past 30 days, on the days you smoked, how many cigarettes did you smoke per day?'. Response options included: 'I did not smoke during the past 30 days', ' $<1 \mathrm{cig} /$ day', ' 1 cig/day', '2-5 cig/day', '6-10 cig/day', '11-20 cig/ day' and '>20 cig/day'. We dichotomized current cigarette smokers as light ( $\leqslant 5 \mathrm{cig} /$ day) or heavy smokers ( $>5 \mathrm{cig} /$ day). Time to first cigarette after waking up was assessed by asking: 'How soon after you wake up do you smoke your first cigarette of the day?'. Response options included: 'I don't smoke', ‘5 minutes', ‘6-30 minutes', ‘31-60 minutes', and 'more than 60 minutes'. We dichotomized the answers into ' $\leqslant 30$ minutes' and ' $>30$ minutes', following previous research on nicotine dependence ${ }^{29}$.

Peer smoking was assessed by asking: 'How many of your close friends smoke?' with response options from 'none' to 'all'. Responses were re-categorized into 3 groups (i.e. none, less than half, and half or more). Knowledge about the harm of cigarette smoking was assessed by asking: 'Do you think smoking is harmful?'. Response options included: 'definitely no', 'probably no', 'probably yes', and 'definitely yes'. We dichotomized the responses as 'good' if 'definitely yes' was checked, and 'poor' for others. Alcohol use was measured by asking: 'How frequently do you drink alcohol or alcoholic beverage?'. Response options included 'I don't drink', '<1 day/month', '1-3 days/month', '1-3 days/week', '4-6 days/week', and 'I drink every day'. Participants were categorized as 'non-drinkers', ' $<1$ day/month', and ' $\geqslant 1$ day/month'.

Quit attempt was assessed by asking: 'During the past 12 months, have you ever tried to quit smoking?'. Quit intention was assessed by asking: 'Do you want to quit smoking now?'. Responses for both questions were dichotomized as 'yes' or 'no'. Sociodemographic variables included students' age, sex and perceived family financial status, which was assessed by asking: 'In your opinion, your family's financial status is on a 5-point Likert scale ranging from 'relatively poor' to 'relatively rich'. Answers were categorized into 'poor', 'average', and 'rich'.

\section{Statistical analysis}

Stata version 13.1 was used for data analysis. Data were weighted using 2012/13 Hong Kong student enrollment statistics to match the sample with the overall secondary school student population. We calculated the weighted prevalence of the 3 tobacco-use groups (i.e. 'cigarette-only smoking', 'exclusive ATP use', and 'concurrent tobacco use'). ANOVA (for continuous variable) and chi-squared (for categorical variables) tests were conducted to compare the 3 groups by sociodemographic and other variables. Among current tobacco users $(n=2$ 831), multinomial logistic regression was used 
to examine the factors associated with exclusive ATP use and concurrent tobacco use relative to cigarette-only smoking. Potential correlates assessed included age, sex, perceived family financial status, peer cigarette smoking, knowledge about the harm of cigarette smoking, and alcohol use. We then conducted separate multivariable logistic regression among current cigarette smokers $(n=1694)$ to examine the relations of concurrent tobacco use with cigarette consumption per day, time to first cigarette after waking up, quit intention and quit attempt, controlling for covariates.

\section{RESULTS}

Table 1 shows the sample characteristics. Overall, $5.8 \%$ (95\% confidence interval [CI]: $5.5-6.2 \%)$ of students reported current tobacco use, including $2.1 \%$ (95\% CI: $2.0-2.3 \%$ ) cigarette-only smokers, 2.5\% (95\% CI: $2.3-2.8 \%$ ) exclusive ATP users, and
$1.2 \%$ (95\% CI: $1.0-1.3 \%$ ) concurrent tobacco users. Waterpipe (1.2\%, 95\% CI: 1.1-1.4\%) and e-cigarettes (1.1\%, 95\% CI: $1.0-1.3 \%)$ were the most popular ATPs used by students, followed by cigars $(1.1 \%$, 95\% CI: $0.9-1.2 \%)$, chewing tobacco $(0.8 \%, 95 \%$ CI: $0.7-1.0 \%)$, snus $(0.6 \%, 95 \%$ CI: $0.5-0.7 \%)$, and nasal snuff (0.5\%, 95\% CI: $0.4-0.6 \%)$ and other noncigarette tobacco products $(0.4 \%, 95 \%$ CI: $0.4-0.5 \%$; data not shown in Tables). Among current cigarette smokers (3.3\% of all respondents), $35.0 \%$ reported concurrent ATP use; among ATP users $(3.7 \%$ of all respondents), $39.0 \%$ reported cigarette smoking (data not shown in Tables). Compared with cigaretteonly smokers, exclusive ATP users and concurrent tobacco users were: younger $(\mathrm{p}<0.001)$, mainly boys $(\mathrm{p}=0.001)$, students who perceived their family as being rich $(\mathrm{p}<0.001)$, those with no cigarette smoking peers $(\mathrm{p}<0.001)$, with poor knowledge about smoking $(\mathrm{p}=0.004)$, and those who consumed

Table 1. Sample characteristics and comparisons of cigarette only smoking, exclusive ATP use, and concurrent tobacco use among Hong Kong adolescents

\begin{tabular}{|c|c|c|c|c|c|c|c|c|c|}
\hline & & & & Curre & tobace & $c^{a}(n-28 s$ & $\left.5.8^{\circ} \%\right)$ & & \\
\hline & $\begin{array}{r}\mathrm{N} / \mathrm{s} \mathrm{s} \\
(\mathrm{N}=158\end{array}$ & lents & $\begin{array}{r}\text { Ciga } \\
5 \\
(n=\end{array}$ & $\begin{array}{l}\text { e only } \\
\text { ing } \\
2.1 \% \text { ) }\end{array}$ & $\begin{array}{l}\text { Exclu } \\
(n=\end{array}$ & $\begin{array}{l}\text { ATP use } \\
2.5 \%)\end{array}$ & $\begin{array}{l}C o \\
\text { tob } \\
(n==\end{array}$ & $\begin{array}{l}\text { rrent } \\
\text { use } e^{b} \\
1.2 \% \text { ) }\end{array}$ & $p$ \\
\hline & n & $\left(\% \%^{c}\right)$ & n & $(\% c)$ & $n$ & $(\% c)$ & n & $(\% c)$ & \\
\hline Age, y (SD) & 14.8 & (1.9) & 15.9 & $(1.8)$ & 15.4 & (2.0) & 15.6 & (1.9) & $<0.001$ \\
\hline Sex & & & & & & & & & 0.001 \\
\hline Girl & 21117 & $(48.6)$ & 450 & $(44.0)$ & 314 & $(32.2)$ & 203 & $(40.2)$ & \\
\hline Boy & 24740 & $(51.4)$ & 660 & $(56.0)$ & 823 & (67.8) & 381 & (59.8) & \\
\hline $\begin{array}{l}\text { Perceived family financial } \\
\text { status }\end{array}$ & & & & & & & & & $<0.001$ \\
\hline Average & 25480 & $(55.6)$ & 599 & $(54.1)$ & 530 & $(45.4)$ & 244 & $(37.8)$ & \\
\hline Poor & 13921 & $(29.4)$ & 397 & $(36.1)$ & 369 & $(33.5)$ & 200 & $(34.8)$ & \\
\hline Rich & 6315 & $(15.0)$ & 110 & $(9.9)$ & 230 & $(21.2)$ & 137 & $(27.3)$ & \\
\hline Peer cigarette smoking & & & & & & & & & $<0.001$ \\
\hline No & 27149 & $(60.9)$ & 28 & $(2.3)$ & 269 & $(23.0)$ & 36 & (8.2) & \\
\hline Less than half & 14568 & (30.8) & 277 & $(24.9)$ & 410 & $(34.3)$ & 117 & $(22.4)$ & \\
\hline Half or more & 4068 & (8.3) & 805 & $(72.8)$ & 444 & $(42.7)$ & 427 & (69.3) & \\
\hline $\begin{array}{l}\text { Knowledge about the harm } \\
\text { of cigarette smoking }\end{array}$ & & & & & & & & & 0.004 \\
\hline Poor & 5235 & $(10.9)$ & 436 & $(38.4)$ & 465 & (43.7) & 302 & (51.5) & \\
\hline Good & 40604 & (89.1) & 647 & $(61.6)$ & 672 & (56.3) & 282 & $(48.5)$ & \\
\hline Alcohol use & & & & & & & & & $<0.001$ \\
\hline Non-drinker & 29633 & (66.8) & 185 & $(18.2)$ & 227 & $(18.6)$ & 66 & $(12.1)$ & \\
\hline$<1$ day/month & 8221 & (18.4) & 246 & $(24.3)$ & 144 & (13.6) & 62 & $(10.4)$ & \\
\hline$\geq 1$ day/month & 6846 & (14.8) & 600 & $(57.5)$ & 734 & (67.8) & 423 & (77.5) & \\
\hline
\end{tabular}

ATP: alternative tobacco product. a Current tobacco users reported cigarette smoking or alternative tobacco use during the past 30 days.

$\mathrm{b}$ Concurrent tobacco use is defined as the use of cigarettes and at least one form of alternative tobacco products during the past 30 days. $\mathrm{c}$ Weighted percentage. 
alcohol on $\geqslant 1$ day/month $(\mathrm{p}<0.001)$.

Exclusive ATP use was associated with younger age (relative risk ratio, $\mathrm{RRR}=0.88$ per year, 95\% CI: 0.81-0.95), male ( $\mathrm{RRR}=1.72,95 \% \mathrm{CI}$ : $1.27-2.34)$, perceived to be 'rich' $(\mathrm{RRR}=2.39$, 1.55-3.68), absence of cigarette smoking peers ( $\mathrm{RRR}=8.47,95 \% \mathrm{CI}: 5.03-14.27)$, poor knowledge about cigarette smoking $(\mathrm{RRR}=1.50,95 \% \mathrm{CI}$ : 1.12-2.01), and alcohol use on $\geqslant 1 \mathrm{day} / \mathrm{month}$ $(\mathrm{RRR}=1.56,95 \% \mathrm{CI}: 1.07-2.26)$, see Table 2 . Similarly, concurrent tobacco use was associated with younger age $(\mathrm{RRR}=0.92,95 \% \mathrm{CI}: 0.84-$ 0.99 ), perceived 'rich' ( $R R R=3.47,95 \%$ CI: $2.20-$ $5.47)$, having no smoking peers ( $\mathrm{RRR}=4.66,95 \%$ CI: 2.18-9.94), poor knowledge about smoking ( $\mathrm{RRR}=1.65,95 \% \mathrm{CI}: 1.20-2.28)$, and alcohol consumption on $\geqslant 1$ day/month $(\mathrm{RRR}=2.18,95 \%$ CI: $1.37-3.46)$.

Among current cigarette smokers, ATP use was not associated with cigarette consumption each day (adjusted odds ratio, AOR $=1.38$, 95\% CI: 0.99$1.91)$ or the time to first cigarette after waking up $(\mathrm{AOR}=1.38,95 \%$ CI: 0.98-1.94), see Table 3 . However, cigarette smokers who used ATP were less likely to have an intention to quit cigarette smoking $(\mathrm{AOR}=0.69,95 \% \mathrm{CI}: 0.50-0.97)$ and quit attempts in the past 12 months $(\mathrm{AOR}=0.67,95 \%$ CI: 0.49-0.92) than cigarette-only smokers. Among cigarette smokers, concurrent use of ATPs was associated with perceiving themselves as being rich, having no cigarette smoking peers, poor knowledge about smoking, and drinking alcohol on $\geqslant 1$ day/ month.
Table 2. Factors associated with exclusive ATP use and concurrent tobacco use relative to cigarette only smoking among current tobacco users

\begin{tabular}{|c|c|c|c|c|}
\hline & \multicolumn{2}{|c|}{$\begin{array}{l}\text { Exclusive ATP use } \\
\text { vs cigarette only }\end{array}$} & \multicolumn{2}{|c|}{$\begin{array}{c}\text { Concurrent tobaceo } \\
\text { use }^{\text {a }} \text { vs cigarette- } \\
\text { only }\end{array}$} \\
\hline & $a R R^{b}$ & {$\left[95^{\circ} \% \mathrm{CI}\right.$} & $a R R R^{b}$ & {$\left[95^{\circ} \circ \mathrm{CI}\right]$} \\
\hline Age & 0.88 & {$[0.81,0.95]^{* *}$} & 0.92 & {$[0.84,0.99]^{*}$} \\
\hline \multicolumn{5}{|l|}{ Sex } \\
\hline Girl & 1.00 & & 1.00 & \\
\hline Boy & 1.72 & {$[1.27,2.34]^{* * *}$} & 1.31 & {$[0.94,1.82]$} \\
\hline \multicolumn{5}{|l|}{$\begin{array}{l}\text { Perceived } \\
\text { family financial } \\
\text { status }\end{array}$} \\
\hline Average & 1.00 & & 1.00 & \\
\hline Poor & 1.14 & {$[0.84,1.53]$} & 1.37 & {$[0.96,1.94]$} \\
\hline Rich & 2.39 & {$[1.55,3.68]^{* * *}$} & 3.47 & {$[2.20,5.47]^{* * *}$} \\
\hline \multicolumn{5}{|l|}{$\begin{array}{l}\text { Peer cigarette } \\
\text { smoking }\end{array}$} \\
\hline Less than half & 1.00 & & 1.00 & \\
\hline No & 8.47 & {$[5.03,14.27]^{* * *}$} & 4.66 & {$[2.18,9.94]^{* * *}$} \\
\hline Half or more & 0.43 & {$[0.32,0.57]^{* * *}$} & 0.97 & {$[0.67,1.41]$} \\
\hline \multicolumn{5}{|l|}{$\begin{array}{l}\text { Knowledge } \\
\text { about the harm } \\
\text { of cigarette } \\
\text { smoking }\end{array}$} \\
\hline Good & 1.00 & & 1.00 & \\
\hline Poor & 1.50 & {$[1.12,2.01]^{* *}$} & 1.65 & {$[1.20,2.28]^{* *}$} \\
\hline \multicolumn{5}{|l|}{ Alcohol use } \\
\hline Non-drinker & 1.00 & & 1.00 & \\
\hline$<1$ day/month & 0.70 & {$[0.45,1.10]$} & 0.72 & {$[0.41,1.25]$} \\
\hline$\geq 1$ day/month & 1.56 & {$[1.07,2.26]^{*}$} & 2.18 & {$[1.37,3.46]^{* *}$} \\
\hline
\end{tabular}

ATP: alternative tobacco product, aRRR: adjusted relative risk ratio, $\mathrm{Cl}$ : confidence interval a Concurrent tobacco use is defined as the use of cigarettes and at least one form of alternative tobacco products during the past 30 days.

Multinomial logistic regression model adjusted for all variables listed in the table. ${ }^{*} \mathrm{p}<0.05 ;{ }^{* *} \mathrm{p}<0.01 ;{ }^{* * *} \mathrm{p}<0.001$

Table 3. Factors associated with concurrent tobacco use among current cigarette smokers

\begin{tabular}{|c|c|c|c|c|c|c|c|c|}
\hline & \multicolumn{8}{|c|}{ Concurrent tobaceo usea } \\
\hline & AOR & {$[95 \%$ CI } & $\mathrm{AOR}^{b}$ & {$[95 \% \mathrm{CI}$} & $A O R^{b}$ & {$\left[95^{\circ} \% \mathrm{CI}\right]$} & $A O R^{b}$ & $195^{\circ} \circ \mathrm{CI}$ \\
\hline Age & 0.93 & {$[0.86,1.01]$} & 0.96 & {$[0.88,1.05]$} & 0.94 & {$[0.86,1.02]$} & 0.94 & {$[0.86,1.02]$} \\
\hline \multicolumn{9}{|l|}{ Sex } \\
\hline Girl & 1.00 & & 1.00 & & 1.00 & & 1.00 & \\
\hline Boy & 1.30 & {$[0.93,1.83]$} & 1.41 & {$[0.98,2.03]$} & 1.29 & {$[0.92,1.80]$} & 1.30 & {$[0.93,1.82]$} \\
\hline \multicolumn{9}{|c|}{ Perceived family financial status } \\
\hline Average & 1.00 & & 1.00 & & 1.00 & & 1.00 & \\
\hline Poor & 1.39 & {$[0.97,1.99]$} & 1.52 & {$[1.04,2.24]^{*}$} & 1.36 & {$[0.95,1.94]$} & 1.40 & {$[0.98,2.00]$} \\
\hline Rich & 3.26 & {$[2.03,5.25]^{* * *}$} & 3.51 & {$[2.10,5.87]^{* * *}$} & 3.23 & {$[2.01,5.19]^{* * *}$} & 3.25 & {$[2.03,5.22]^{* * *}$} \\
\hline \multicolumn{9}{|c|}{ Peer cigarette smoking } \\
\hline Less than half & 1.00 & & 1.00 & & 1.00 & & 1.00 & \\
\hline No & 3.88 & {$[1.93,7.80]^{* * *}$} & 6.23 & {$[2.81,13.81]^{* * *}$} & 4.12 & {$[2.07,8.18]^{* * *}$} & 4.19 & {$[2.06,8.51]^{* * *}$} \\
\hline
\end{tabular}


Table 3. Continued

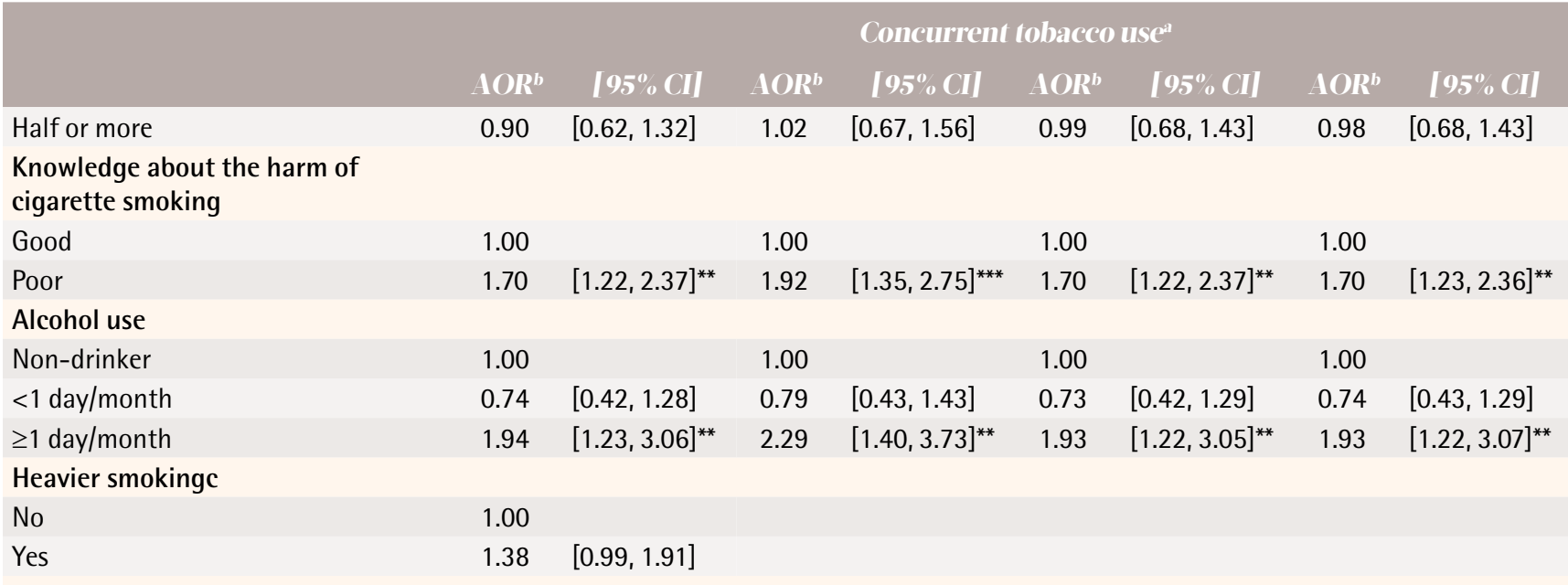

Time to 1 st cigarette on waking

$>30$ minutes

$\leq 30$ minutes

$1.38[0.98,1.94]$

Quit intention

No

1.00

$0.69[0.50,0.97]^{*}$

Quit attempt

No

Yes

0.67

$[0.49,0.92]^{*}$

AOR: adjusted odds ratio, $\mathrm{Cl}$ : confidence interval. a Concurrent tobacco use is defined as the use of cigarettes and at least one form of alternative tobacco products during the past 30 days. b Multivariable logistic regression models adjusted for age, sex, perceived family financial status, peer cigarette smoking, knowledge about the harm of cigarette smoking, and alcohol use. cheavier smoking is defined as $>5$ cigarettes per day. ${ }^{*} p<0.05 ;{ }^{* *} p<0.01 ;{ }^{* * *} p<0.001$.

\section{DISCUSSION}

This is the first study in Asia to compare the different types of tobacco users (i.e. cigaretteonly smokers, exclusive ATP users, and concurrent users of cigarettes and ATPs) using a large representative sample of adolescents. It is among the few studies that examine the correlates of ATP use (exclusively and in combination with cigarette smoking) compared with cigarette-only smoking. ATP use $(3.7 \%)$ was as prevalent as cigarette smoking (3.3\%) among adolescents, with waterpipe and e-cigarettes being the most popular forms of $\mathrm{ATPs}^{27}$. This finding is alarming. Emerging tobacco products, particularly waterpipe and e-cigarettes, usually target young people $\mathrm{e}^{30}$ and attract them with pleasant flavors and stylish designs. However, Hong Kong's comprehensive tobacco control programs rarely discuss other forms of tobacco products. The prevalent ATP use in adolescents reflects the popularity of ATPs (particularly waterpipe and e-cigarettes) in the market, which may continue to expand with aggressive promotions. Policies prohibiting the use of flavors in all tobacco products and prohibiting the promotion and sale of all tobacco products to minors may help prevent the initiation of ATP use in adolescents. Surveillance systems should continuously monitor the use of all tobacco products. Prevention and intervention programs must address a wide range of tobacco products in addition to cigarettes.

Forty percent of adolescent tobacco users reported exclusive ATP use. It is of particular concern, as longitudinal studies among cigarette-naïve youth have found, that ATP use is a significant predictor of subsequent cigarette smoking ${ }^{31-33}$. Another longitudinal study has concluded that e-cigarette use among never-cigarette smoking adolescents is predictive of future initiation of cigarettes, cigars and waterpipe ${ }^{34}$. We also found that ATP use was prevalent among cigarette smokers, with $35.0 \%$ of cigarette smokers reporting concurrent use of ATPs. Concurrent use of cigarettes and ATPs may lead to increased cigarette consumption and the use of more different forms of tobacco products. A study of 
Danish adolescents has found that cigarette smokers who used waterpipe were more likely to report increased cigarette smoking intensity at followup than their counterparts who smoked cigarettes only $^{35}$. Saunders and Geletko ${ }^{36}$ found that adolescent cigarette smokers who used one form of ATP were more likely to use other types of ATPs. More research is warranted to examine the trajectory of cigarette smoking and ATP use among Asian adolescents and to assess how the use of one form of tobacco product (i.e. cigarette or ATP) would affect the initiation and use pattern of other tobacco products.

Compared with cigarette-only smokers, exclusive ATP users and concurrent tobacco users were younger. This finding is in line with previous studies $^{37,38}$. Interestingly, relative to cigarette-only smoking, adolescents with higher perceived family financial status were more likely to report exclusive ATP use and concurrent tobacco use. It may reflect the different marketing targets as ATPs are usually more expensive than conventional cigarettes in Hong Kong. Researchers should better understand the marketing tactics of different tobacco products and how the marketing would affect youth's perceptions about different tobacco products and their use patterns.

Relative to cigarette-only smokers, students with no cigarette smoking peers were more likely to report exclusive ATP use and concurrent tobacco use. It suggests that cigarette smokers and ATP users are two different communities despite some overlap between the two groups (35\% of cigarette smokers and $39 \%$ of ATP users are concurrent tobacco users). A previous study found that peer use of noncigarette tobacco products was correlated with ATP use among adolescent cigarette smokers ${ }^{39}$. We had no information about peer ATP use in this study. Future research should assess peer ATP use and how it would influence youth tobacco use.

Poor smoking knowledge was correlated with exclusive ATP use and concurrent tobacco use. In Hong Kong, school-based anti-tobacco education programs focus on cigarette smoking and now include materials related to ATPs. The Survey did not measure students' knowledge on ATPs. But the messaging on the negative health consequences of cigarette smoking appears to protect school children from using other tobacco products. Consistent with previous studies ${ }^{17,40-42}$, we found that exclusive ATP use and concurrent tobacco use were associated with more frequent alcohol consumption. As noted in other studies, adolescent cigarette smokers who used ATPs were more prone to engage in other risk behaviors, such as drunk drinking ${ }^{40}$ and illicit drug use ${ }^{18,40,41}$, than cigarette-only smokers. Future tobacco control interventions for youth need to address alcohol use, collectively.

Notably, among cigarette smokers, ATP use was negatively associated with quit intention and attempt. It raises the concern that concurrent tobacco users may be less able to quit cigarette smoking than their peers who smoke cigarettes exclusively. Future tobacco interventions should address the use of all tobacco products and not just cigarette smoking.

Concurrent tobacco use was not associated with cigarette smoking intensity or the time to first cigarette after waking up. Potential reasons might be that many concurrent users in our sample used nicotine-free e-cigarettes or waterpipe, and that ATP use was infrequent. Our results are not in agreement with previous studies; Wang and colleagues $^{43}$ found that e-cigarette use in adolescent cigarette smokers was associated with heavier cigarette smoking intensity. Lee et al. ${ }^{16}$ and Post et al. ${ }^{12}$ found that cigarette smokers who used ATPs were more likely to report tobacco use within the first 30 minutes of waking up. The contradictory findings might be explained by three factors. First, our study focused on a wider range of tobacco products, whereas previous studies focused on a single form of ATP (e.g. e-cigarettes ${ }^{43}$ or snus ${ }^{12}$ ). Second, we coded the outcome of cigarette smoking intensity as a dichotomous categorical variable, whereas the prior study treated it as a continuous variable $^{43}$. Third, the adolescent populations were from different regions of the world ${ }^{12}$. Further research is needed to examine if and how ATP use would affect nicotine dependence among Asian adolescents.

This study has several limitations. First, the crosssectional study design limits the inferences about causality. Second, data might not be representative of all adolescents in Hong Kong as participants are school students (excluding special schools). Third, we have no information about the frequency and 
intensity of ATP use. Thus, we cannot determine whether the ATP users were merely experimenting with ATPs or established users. Fourth, the response rate at school level is low. However, we compared the characteristics of participating schools and students with Hong Kong Education Bureau's data on schools and students; the small to medium Cohen's effect sizes indicate that our findings are unlikely to be biased. Finally, the self-reported data are subject to recall and reporting bias.

\section{CONCLUSIONS}

This study has important implications for tobacco control practice. First, it demonstrates that the use of non-conventional tobacco products is as prevalent as cigarette smoking among adolescents, suggesting that tobacco control programs must address a full array of tobacco products in the surveillance, prevention and intervention efforts. Second, exclusive ATP users and concurrent tobacco users are different from cigarette-only smokers in many demographic and psychosocial factors, and ATP use is negatively associated with cigarette smoking quit intention and quit attempt. Health educators and tobacco cessation professionals need to develop tailored interventions for different types of tobacco users. Third, the significant clustering of tobacco and alcohol use suggests that tobacco prevention and intervention programs should address alcohol consumption, collectively.

\section{REFERENCES}

1. U.S. Department of Health and Human Services. Preventing tobacco use among youth and young adults: A report of the Surgeon General. Atlanta, GA: U.S. Department of Health and Human Services, Centers for Disease Control and Prevention, National Center for Chronic Disease Prevention and Health Promotion, Office on Smoking and Health; 2012.

2. Centers for Disease Control and Prevention. Tobacco product use among middle and high school students United States, 2011 and 2012. Morb Mortal Wkly Rep 2013;62(45):893-897.

3. Arrazola RA, Singh T, Corey CG, Husten CG, Neff LJ, Apelberg BJ, et al. Tobacco use among middle and high school students - United States, 2011-2014. Morb Mortal Wkly Rep 2015;64(14):381-385.

4. Goniewicz ML, Gawron M, Nadolska J, Balwicki L,
Sobczak A. Rise in electronic cigarette use among adolescents in Poland. J Adolesc Health 2014;55(5):713715. doi: 10.1016/j.jadohealth.2014.07.015

5. White J, Li J, Newcombe R, Walton D. Tripling use of electronic cigarettes among New Zealand adolescents between 2012 and 2014. J Adolesc Health 2015;56(5):522-528. doi: 10.1016/j.jadohealth.2015.01.022

6. Eissenberg T, Shihadeh A. Waterpipe tobacco and cigarette smoking: Direct comparison of toxicant exposure. Am J Prev Med 2009;37(6):518-523. doi: 10.1016/j.amepre.2009.07.014

7. Goniewicz ML, Knysak J, Gawron M, Kosmider L, Sobczak A, Kurek J, et al. Levels of selected carcinogens and toxicants in vapour from electronic cigarettes. Tob Control 2013;23(2):133-139. doi: 10.1136/tobaccocontrol-2012-050859

8. Baker F, Ainsworth SR, Dye JT, Crammer C, Thun MJ, Hoffmann D, et al. Health risks associated with cigar smoking. JAMA 2000;284(6):735-740. doi: 10.1001/jama.284.6.735

9. Fagerström K, Eissenberg T. Dependence on tobacco and nicotine products: A case for product-specific assessment. Nicotine Tob Res 2012;14(11):1382-1390. doi: $10.1093 / \mathrm{ntr} / \mathrm{nts} 007$

10. DiFranza JR, Sweet M, Savageau JA, Ursprung WWS. The assessment of tobacco dependence in young users of smokeless tobacco. Tob Control 2012;21(5):471-476. doi: 10.1136/tc.2011.043810

11. Aboaziza E, Eissenberg T. Waterpipe tobacco smoking: What is the evidence that it supports nicotine/tobacco dependence? Tob Control 2015;24(Suppl 1):i44-i53. doi: 10.1136/tobaccocontrol-2014-051910

12. Post A, Gilljam H, Rosendahl I, Bremberg S, Galanti MR. Symptoms of nicotine dependence in a cohort of Swedish youths: a comparison between smokers, smokeless tobacco users and dual tobacco users. Addiction 2010;105(4):740-746. doi: 10.1111/j.1360-0443.2009.02852.x

13. Jiang N, Wang MP, Ho SY, Leung LT, Lam TH. Electronic cigarette use among adolescents: A crosssectional study in Hong Kong. BMC Public Health 2016;16(1):202. doi: 10.1186/s12889-016-2719-4

14. Dutra LM, Glantz SA. High international electronic cigarette use among never smoker adolescents. J Adolesc Health 2014;55(5):595-597. doi: 10.1016/j.jadohealth.2014.08.010

15. Berg CJ, Schauer GL, Asfour OA, Thomas AN, Ahluwalia JS. Psychosocial factors and healthrisk behaviors associated with hookah use among college students. J Addict Res Ther 2011(Suppl 2). doi: 10.4172/2155-6105.S2-001

16. Lee YO, Hebert CJ, Nonnemaker JM, Kim AE. Youth tobacco product use in the United States. Pediatrics 2015;135(3):409-415. doi: 10.1542/peds.2014-3202 
17. Wickholm S, Galanti MR, Söder B, Gilljam H. Cigarette smoking, snuff use and alcohol drinking: coexisting risk behaviours for oral health in young males. Community Dent Oral Epidemiol 2003;31(4):269-274. doi: 10.1034/j.1600-0528.2003.00046.x

18. Cavazos-Rehg PA, Krauss MJ, Spitznagel EL, Grucza RA, Bierut LJ. Youth tobacco use type and associations with substance use disorders. Addiction 2014;109(8):13711380. doi: 10.1111/add.12567

19. The Government of the Hong Kong Special Administrative Region. Thematic Household Survey: Report No. 59. Hong Kong: The Government of the Hong Kong Special Administrative Region, Census and Statistics Department; 2016.

20. The Government of the Hong Kong Special Administrative Region. Smokeless Tobacco Products (Prohibition) Regulations. The Government of the Hong Kong Special Administrative Region, Customs and Excise Department. Hong Kong; 1997.

21. Tsang E. In Hong Kong, e-cigarettes are as available to children as candy. South China Morning Post. April 8, 2015. http://www.scmp.com/news/hong-kong/ article/1759634/hong-kong-e-cigarettes-are-availablechildren-candy. Accessed July 14, 2015.

22. Du F. Teenage girl felt faint in bar due to waterpipe smoking. Wen Wei Po. May 28, 2011;Sect. A16. http:// pdf.wenweipo.com/2011/05/28/a16-0528.pdf. Accessed June 18, 2015.

23. The Government of the Hong Kong Special Administrative Region. Tobacco control legislation: Statutory no smoking areas. March 15, 2016. https:// www.tco.gov.hk/english/legislation/legislation_sa.html. Accessed June 18, 2016.

24. Health worries may cloud fun of shisha smoking fad. South China Morning Post. March 25, 2012. http:// www.scmp.com/article/996493/health-worries-maycloud-fun-shisha-smoking-fad. Accessed February 20, 2018.

25. Vansickel AR, Shihadeh A, Eissenberg T. Waterpipe tobacco products: nicotine labelling versus nicotine delivery. Tob Control 2012;21(3):377-379. doi: 10.1136/tc.2010.042416

26. A million times more harmful than outdoor air: Hong Kong study raises e-cigarette cancer alarm. South China Morning Post. February 29, 2016. http://www.scmp.com/news/hong-kong/healthenvironment/article/1918571/million-times-moreharmful-outdoor-air-hong-kong. Accessed February $18,2018$.

27. Jiang N, Ho SY, Wang MP, Leung LT, Lam TH. Waterpipe smoking among secondary school students in Hong Kong. International Journal of Public Health 2016;61(4):427-434. doi: 10.1007/s00038-016-0796-x

28. Wang MP, Ho SY, Leung LT, Lam TH. E-cigarette use and respiratory symptoms in Chinese adolescents in Hong Kong. JAMA Pediatrics 2015;170(1):89-91. doi: 10.1001/jamapediatrics.2015.3024

29. Fagan P, Augustson E, Backinger CL, O'Connell ME, Vollinger RE, Kaufman A, et al. Quit attempts and intention to quit cigarette smoking among young adults in the United States. Am J Public Health 2007;97(8):14121420. doi: 10.2105/AJPH.2006.103697

30. Jiang N, Ho SY, Lam TH. Electronic cigarette marketing tactics in mainland China. Tob Control 2017;26(2):230232. doi: 10.1136/tobaccocontrol-2015-052824

31. Soneji S, Sargent JD, Tanski SE, Primack BA. Associations between initial water pipe tobacco smoking and snus use and subsequent cigarette smoking: Results from a longitudinal study of US adolescents and young adults. JAMA Pediatrics 2015;169(2):129-136. doi: 10.1001/jamapediatrics.2014.2697

32. Jaber R, Madhivanan P, Veledar E, Khader Y, Mzayek F, Maziak W. Waterpipe a gateway to cigarette smoking initiation among adolescents in Irbid, Jordan: A longitudinal study. Int J Tuberc Lung Dis 2015;19(4):481-487. doi: 10.5588/ijtld.14.0869

33. Mzayek F, Khader Y, Eissenberg T, Al Ali R, Ward KD, Maziak W. Patterns of water-pipe and cigarette smoking initiation in schoolchildren: Irbid longitudinal smoking study. Nicotine Tob Res 2012;14(4):448-454. doi: $10.1093 / \mathrm{ntr} / \mathrm{ntr} 234$

34. Leventhal AM, Strong dR, Kirkpatrick MG, Unger JB, Sussman S, Riggs NR, et al. Association of electronic cigarette use with initiation of combustible tobacco product smoking in early adolescence. JAMA 2015;314(7):700-707. doi: 10.1001/jama.2015.8950

35. Jensen PD, Cortes R, Engholm G, Kremers S, Gislum M. Waterpipe use predicts progression to regular cigarette smoking among Danish youth. Subst Use Misuse 2010;45(7-8):1245-1261. doi: 10.3109/10826081003682909

36. Saunders C, Geletko K. Adolescent cigarette smokers' and non-cigarette smokers' use of alternative tobacco products. Nicotine Tob Res 2012;14(8):977-985. doi: $10.1093 / \mathrm{ntr} / \mathrm{ntr} 323$

37. Enofe N, Berg CJ, Nehl EJ. Alternative tobacco use among college students: Who is at highest risk? Am J Health Behav 2014;38(2):180-189. doi: 10.5993/AJHB.38.2.3

38. Bombard JM, Rock VJ, Pederson LL, Asman KJ. Monitoring polytobacco use among adolescents: Do cigarette smokers use other forms of tobacco? Nicotine Tob Res 2008;10(11):1581-1589. doi: 10.1080/14622200802412887

39. Gilpin EA, Pierce JP. Concurrent use of tobacco products by California adolescents. Prev Med 2003;36(5):575584. doi: 10.1016/S0091-7435(02)00064-6

40. Coogan PF, Geller A, Adams M. Prevalence and correlates of smokeless tobacco use in a sample of Connecticut students. J Adolesc 2000;23(2):129-135. 
doi: $10.1006 /$ jado.2000.0303

41. Bombard JM, Pederson LL, Koval JJ, O’Hegarty M. How are lifetime polytobacco users different than current cigarette-only users? Results from a Canadian young adult population. Addict Behav 2009;34(12):1069-1072. doi: 10.1016/j.addbeh.2009.06.009

42. Everett SA, Malarcher AM, Sharp DJ, Husten CG, Giovino GA. Relationship between cigarette, smokeless tobacco, and cigar use, and other health risk behaviors among U.S. high school students. J Sch Health 2000;70(6):234-240. doi: 10.1111/j.1746-1561.2000.tb07424.x

43. Wang MP, Ho SY, Leung LT, Lam TH. Electronic cigarette use and its association with smoking in Hong Kong Chinese adolescents. Addict Behav 2015;50:124127. doi: 10.1016/j.addbeh.2015.06.037

CONFLICTS OF INTEREST

Authors have completed and submitted the ICMJE Form for Disclosure of Potential Conflicts of Interest and none was reported.

FUNDING

The School-based Survey on Smoking among Students was commissioned by the Food and Health Bureau, the Government of the Hong Kong Special Administrative Region of the People's Republic of China. The Government played no role in the conduct of the research, data analysis or interpretation, preparation of the manuscript, or decision to submit this paper for publication.

PROVENANCE AND PEER REVIEW

Not commissioned; externally peer reviewed. 